\title{
Modified transtibial versus anteromedial portal techniques for anterior cruciate ligament reconstruction, a comparative study
}

This article was published in the following Dove Press journal: Open Access Journal of Sports Medicine

\author{
Ehab Abdelbaki Hussin' \\ Asim Aldaheri' \\ Hatem Alharbi' \\ Hazem A Farouk ${ }^{2}$ \\ 'Orthopedics Department, King Fahd \\ Armed Forces Hospital, Jeddah, Saudi \\ Arabia; ${ }^{2}$ Orthopedics Department, \\ Faculty of Medicine, Cairo University, \\ Cairo, Egypt
}

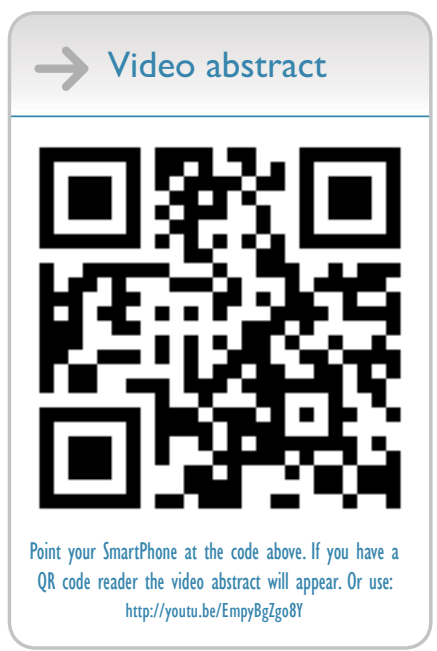

Correspondence: Ehab Abdelbaki Hussin Orthopedics Department, King Fahd Armed Forces Hospital, PO Box: 9862, Courniche Street, Jeddah 2II59,

Saudi Arabia

Tel +96659 1808444

Email ehabelgiar@yahoo.com
Purpose: This study compared the accessory anteromedial portal (AAMP) and the modified transtibial technique (MTTT)" for single-bundle anterior cruciate ligament (ACL) reconstruction. Patients and methods: Sixty active adult patients with ACL tear were randomly assigned into two equal groups who were treated surgically. One group was operated on using AAMP and the other group through MTTT. Both the groups had the same postoperative course and were followed for 1 year after surgery. The follow-up included Lysholm and International Knee Documentation Committee (IKDC) subjective knee evaluation forms, IKDC objective knee examination form, and radiological evaluation. Results were evaluated and compared with each other.

Results: There was no significant difference in subjective effects or clinical examination between the two groups. Regarding radiological angles, the AAMP had more oblique graft orientation in the coronal plane than the MTTT, but both were found to be more slanted than native ACL. Also, the MTTT had succeeded to place the graft and tunnel more obliquity than the traditional non-anatomic TTT and better than the anatomic ranges despite having the graft inclination of the AAMP higher than the MTTT. The complaints from the patients and subjective scoring were found to be positively related to graft stability. Patients with healthier preoperative subjective state had a smoother postoperative period and better outcome.

Conclusion: This study offers simple modifications to the transtibial technique to allow near anatomic ACL reconstruction with similar results comparable to the AAMP and with fewer complications.

Keywords: anterior cruciate ligament, MTTT, AAMP, arthroscopy, orthopedics, ACL, Modified transtibial, anatomic, Arthroscopy, orthopedics

\section{Introduction}

Autograft or allograft arthroscopic single-bundle (SB) is the "gold standard" technique for anterior cruciate ligament (ACL) reconstruction. ${ }^{1}$ It is a universal procedure that has success rates of $83 \%-95 \%$. Recently, many researchers have presumed that the SB transtibial ACL reconstruction places the graft in a non-anatomical femoral insertion site, which largely is considered the most common cause of ACL reconstruction failure. $^{2-9}$ To avoid this common complication, the use of the anteromedial portal (AMP) for drilling the femoral tunnel was suggested as a method to place the graft in an anatomical position and improve rotational stability. ${ }^{2,7,9-14}$ In the Transtibial technique, the location of the femoral tunnel is dictated by the tibial tunnel while the AMP technique provides the surgeon with a higher freedom to place the graft in the anatomical position without being guided by the tibial tunnel. ${ }^{10,13}$ Similar results were 
found in radiographic comparison study in which drilling femoral tunnel through arthroscopic anteromedial portal resulted in radiographic femoral tunnel position which was suggested to allow stabilization of anterior tibial translation and rotational stability when using SB technique. ${ }^{15}$ When anatomic femoral tunnel apertures are allowed consistently, the AM technique introduces new technical challenges. These challenges occur in part because the knee must be hyperflexed with difficulty to obtain a clear view of the lateral wall of the notch. Moreover, the trans-portal pathway with this technique and the resultant horizontal trajectory of wire drilling and reaming may lead to articular cartilage damage, posterior cortical breakthrough, and critically short femoral tunnels, which makes graft passage more tedious. ${ }^{16}$

The current study suggests certain modifications to the traditional TT portal technique aiming to improve its efficiency regarding graft stability and clinical and radiological results. This is compared to the literature-preferred procedure, namely the AMP technique, to determine their superiority over each other. It is hypothesized that this modified technique will give comparable results relevant to those of the accessory AAMPT.

\section{Patients and methods}

The proposed study is a prospective, single-blinded, randomized controlled trial. Participants in this research had ACL tear of one of their knees and planned for ACL reconstruction. Their ACL would be reconstructed using either modified transtibial "MTTT" or anteromedial "AAMPT" technique. They were randomly allotted to either of the two techniques using computer-generated random tables and closed envelope method. After diagnostic arthroscopy, the inclusion/exclusion criteria were applied to select the participants for the study. Thirty patients were allotted for each technique with a total of 60 participants in the study. A single prime surgeon performed all the surgeries. Gracilis and semitendinosus tendon grafts were harvested using the same technique. After harvest, either of the two techniques was implemented to proceed with the reconstruction. Cases were done on day surgery basis. Removal of sutures was done after 2 weeks and follow-up in our clinics after 1, 3, 6 , and 12 months postoperatively.

\section{Ethical approval and consenting}

The research and ethics committee of our institution, King Fahd Armed Forces Hospital, provided approval for the research before commencement (reference ethical
number-REC 184). Written informed consent to participate in this study was signed by every participating patient.

\section{Age and sex}

All our patients were men aged between 19 and 39 years.

\section{Inclusion criteria}

Young, active patients with single knee ACL tear and consequent functional instability with no other ipsilateral knee injuries except simple unrepairable meniscal tears were included in this study.

\section{Exclusion criteria}

1. Participants who were unfit for surgery due to a medical comorbidity.

2. Skeletally immature patients with open physis around the knee.

3. Patients who have osteoarthritis of the ipsilateral knee.

4. Patients who have posterior cruciate ligament, medial collateral ligament or lateral collateral ligament injuries.

5. Patients with complex meniscal injuries that need meniscal repair.

\section{Pre-injury level of activity}

According to the International Knee Documentation Committee (IKDC) evaluation form 16, the pre-injury activity levels of the patients were defined in Table 1.

\section{Original knee injury}

The knee injuries of the patients in the study were classified according to the IKDC form 16 in Table 2. Most of the injuries were due to contact sports.

Table I Pre-injury activity level

\begin{tabular}{ll}
\hline Activity level & $\mathbf{N}$ \\
\hline I: Jumping, pivoting, hard cutting, football & 46 \\
II: Heavy manual work, skiing, tennis & 10 \\
III: Light manual work, jogging, running & 4 \\
IV: Sedentary work (ADL) & 0 \\
Total & 60
\end{tabular}

Abbreviation: $A D L$, activity of daily living.

Table 2 Original knee injury

\begin{tabular}{ll}
\hline Original knee injury & $\mathbf{N}$ \\
\hline I: Activity of daily living & 2 \\
II: Road Accidents & 5 \\
III: Work & 15 \\
IV: Contact sports & 38 \\
Total & 60 \\
\hline
\end{tabular}


Table 3 Time interval between ACL injury and reconstruction

\begin{tabular}{ll}
\hline Time interval & $\mathbf{N}$ \\
\hline Up to 6 months & 26 \\
$>6$ months to I year & 21 \\
$>$ I year to I8 months & 10 \\
$>18$ months to $<2$ years & 3 \\
Total & 60
\end{tabular}

\section{Time interval}

Time elapsed between injury and surgical intervention ranged from 1 to 23 months (Table 3). The mean interval $( \pm$ SD) for the transtibial group was $8.3 \pm 5.0$ months. For the anteromedial group, the mean interval $( \pm \mathrm{SD})$ was $11.5 \pm 6.2$ months.

\section{Concomitant meniscal injuries}

During arthroscopy, 17 patients out of the 60 were found to have meniscal injuries that were non-amenable to repair. Twelve of them had their surgeries done after the mean interval of the study -8.5 months. Partial meniscectomies were performed for 15 patients and subtotal meniscectomies were performed for two patients.

\section{Previous knee surgeries}

None of our patients had any prior knee surgeries.

\section{Mean follow-up period}

Patients were followed up on a regular basis for a total period of 1 year postoperatively. The follow-up visits were at 1 month, 3 months, 6 months, and 1 year from the time of surgery. None of them were dropped out during the follow-up period.

\section{Methods of evaluation}

Patients were evaluated subjectively, objectively, instrumentally, and radiologically. Patients have been scored preoperatively and postoperatively at each postoperative visit. The ranges and mean values of the postoperative scores were assessed. The results of these scoring systems at the end of 1 year were considered the final results.

The subjective assessment was done using two questionnaire systems, namely IKDC subjective knee evaluation form ${ }^{17}$ and the Lysholm scoring system. ${ }^{18}$ These questionnaire forms were translated into Arabic language (mother language of the patients) to guarantee utmost convenience.

For objective assessment, we used the IKDC knee examination form. ${ }^{18}$ This form includes:

- Clinical examinations such as knee range of motion, anterior drawer test, Lachman test, pivot shift test, and functional one-leg hop test for distance. ${ }^{19}$

- Instrumental examination using goniometer and digital rolimeter (Figure 1).

Regarding radiological assessment, specific measurements were estimated on the magnetic resonance imaging, X-ray A-P views and lateral views, which include:

- Sagittal tibial graft angle (TGA) of the operated knee compared with the sagittal intact ACL angle of the contralateral healthy knee (Figure 2). ${ }^{5,21}$

- Graft inclination angle (GIA) compared with femoral graft angle (FGA) of the same knee (Figure 3). ${ }^{5,20,21}$

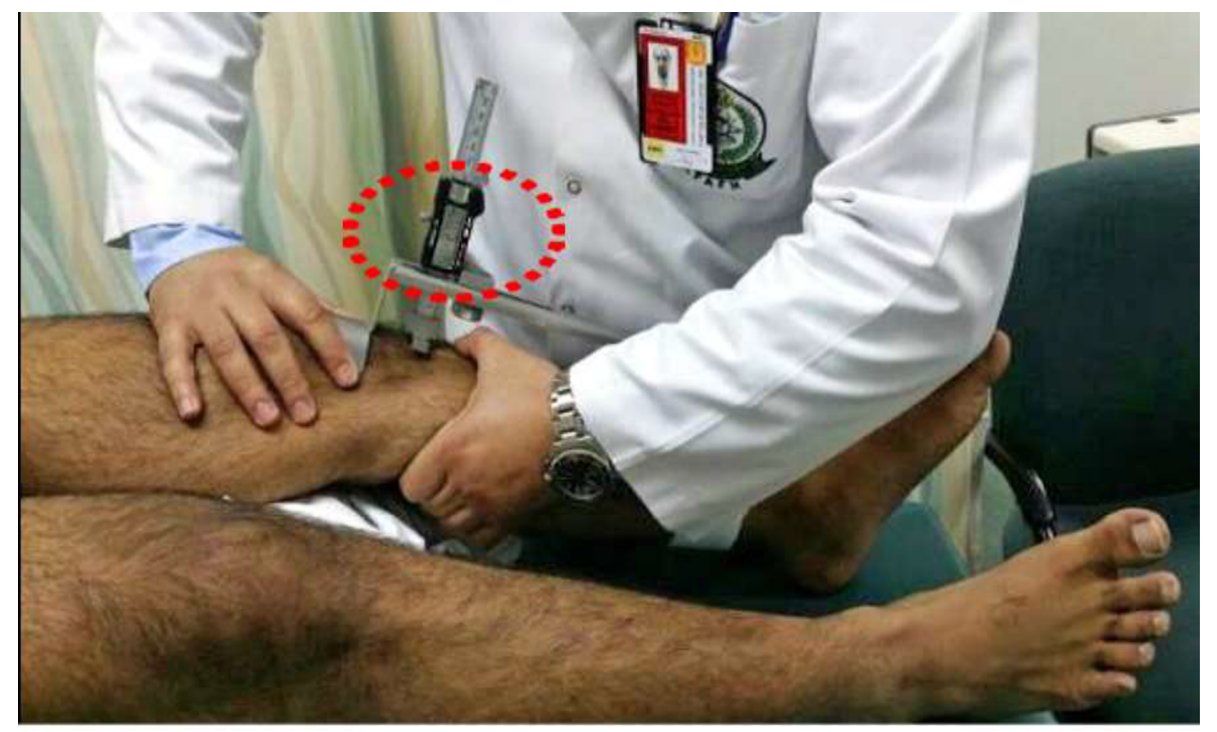

Figure I Digital rolimiter. 
- Femoral tunnel placement (FTP) in the coronal and sagittal planes (Figure 4). ${ }^{21,23}$

- Tibial tunnel placement (TTP) in the coronal and sagittal planes (Figure 5). ${ }^{21,22}$

\section{Surgical steps}

ACL reconstruction was performed in patients of one group using the accessory AAMPT. In the other group of patients, their ACLs were reconstructed by using the MTTT. It is similar to the traditional transtibial technique (TTT) except for certain modifications. ${ }^{23-25}$
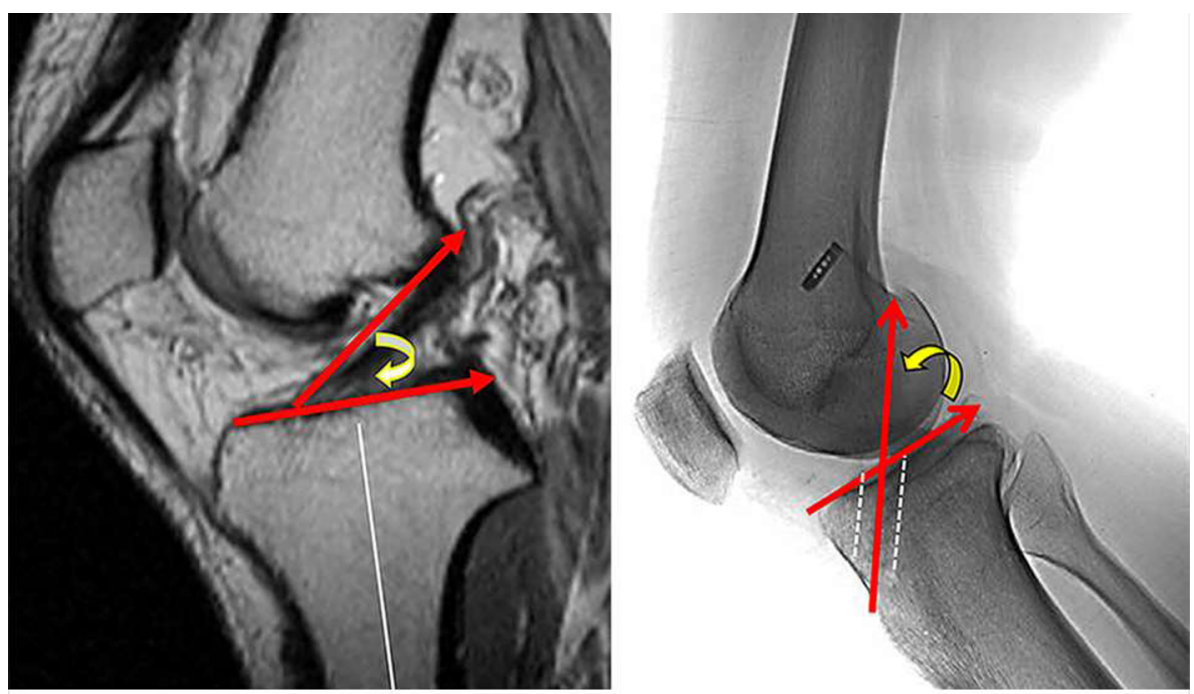

Figure $2 \mathrm{ACL}$ sagittal angle vs tibial graft angle.

Abbreviation: $\mathrm{ACL}$, anterior cruciate ligament.

\section{Tibial tunnel}

The tibial tunneling in this technique is identical to the conventional way but with certain changes:

- Tibial tunnel starting point is about $20 \mathrm{~mm}$ below the medial plateau and about $20 \mathrm{~mm}$ from the edge of the tibial tubercle (Figure 6).

- The tibial drill guide is angled 40 degrees (Figure 6).

- The tibial drill guide is positioned at 40 degrees to the long tibial axis in the coronal plane (Figure 7).

- The tibial guide tip is positioned over the tibial plateau medial to the conventional site (triangular zone cornered

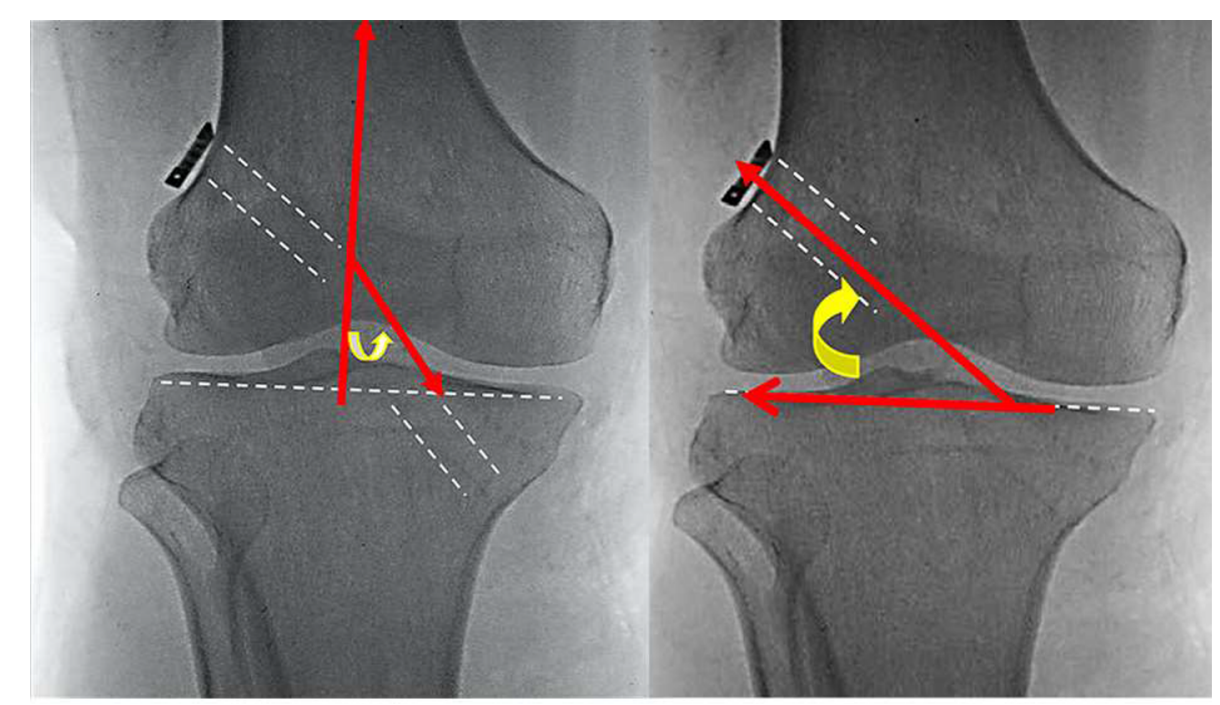

Figure 3 Graft inclination angle vs femoral graft angle. 

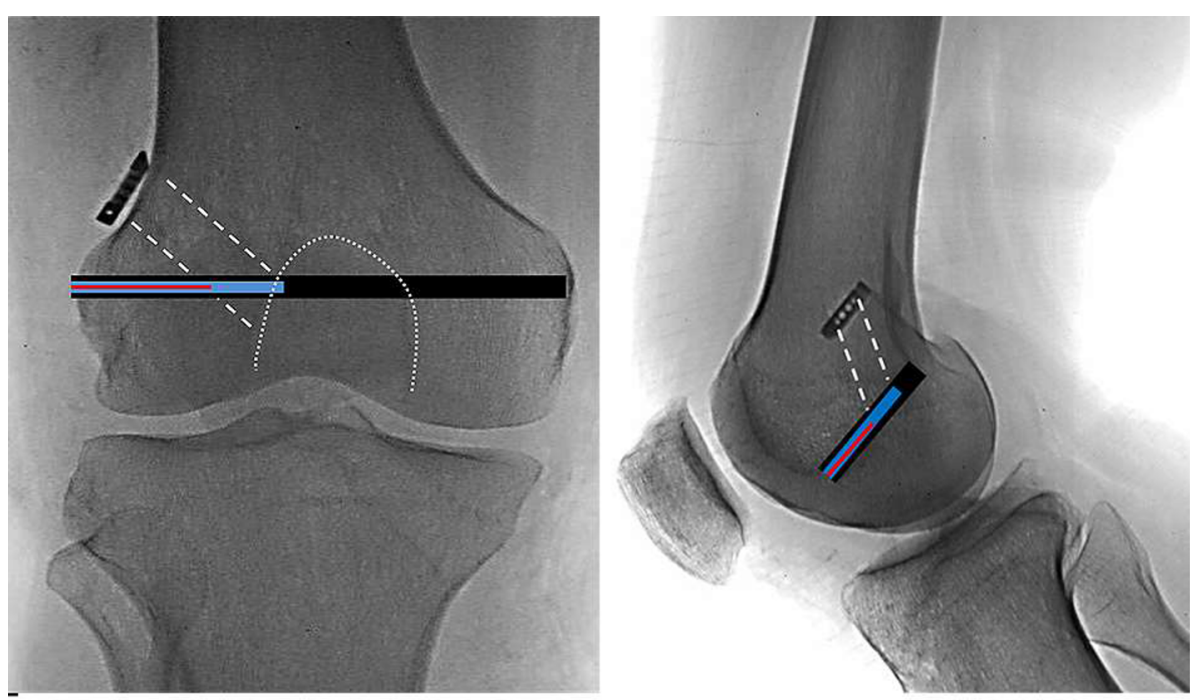

Figure 4 Femoral tunnel placement.
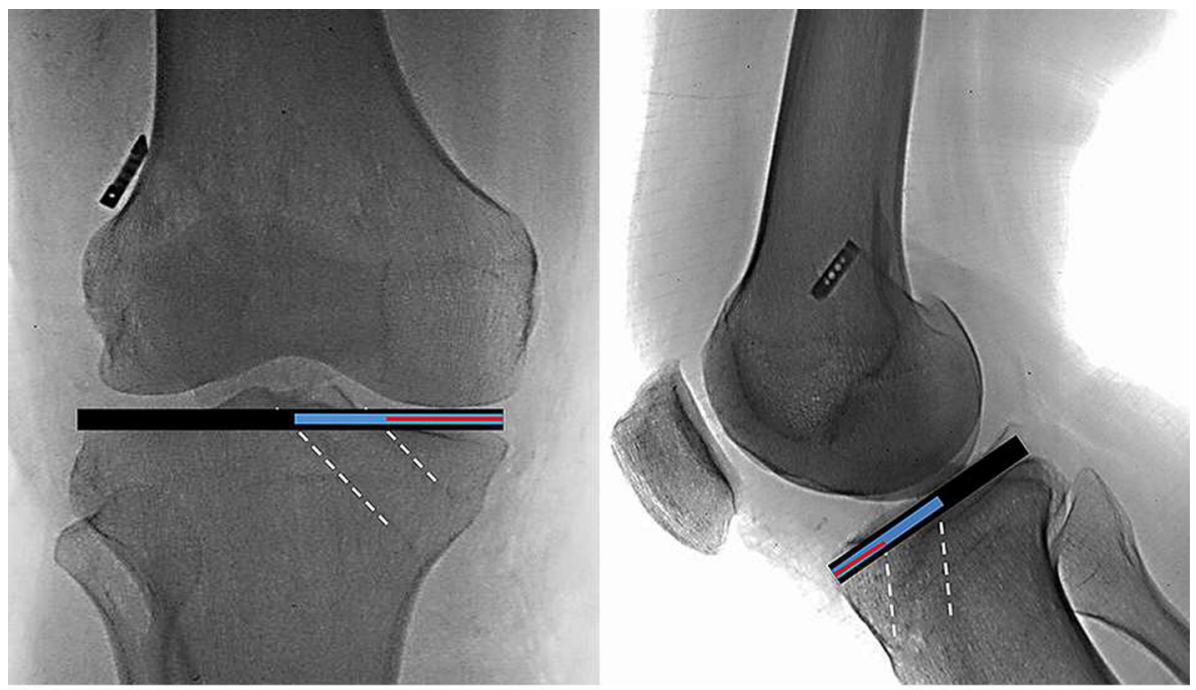

Figure 5 Tibial tunnel placement.
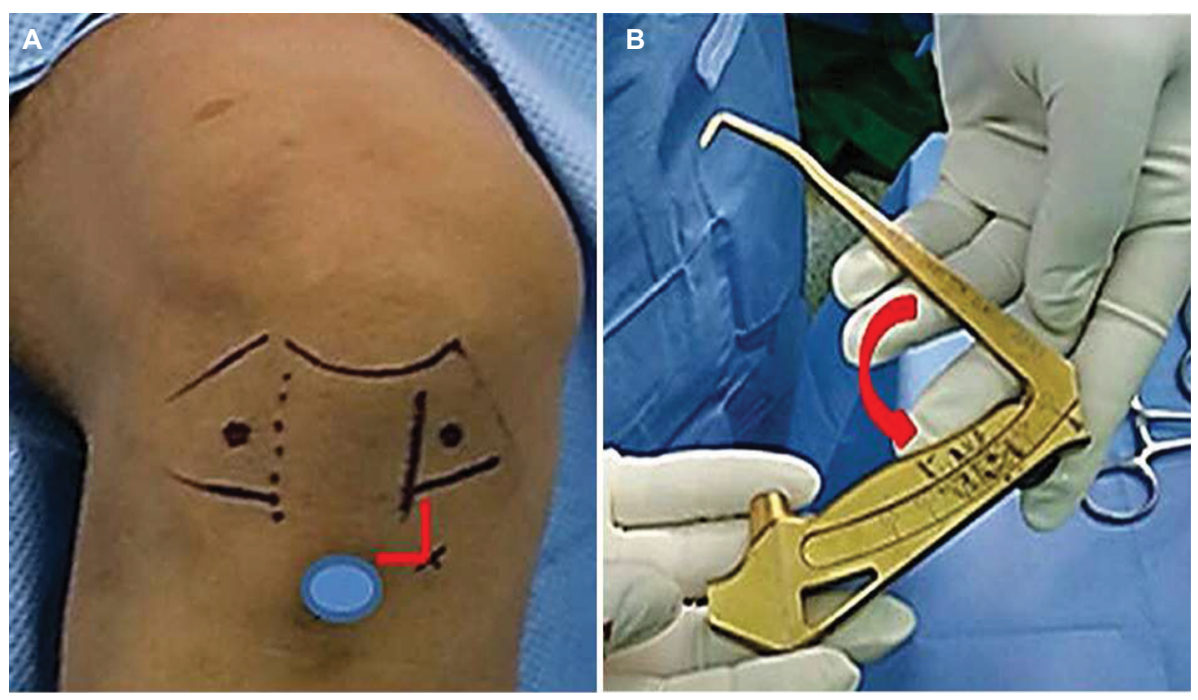

Figure 6 Tibial tunnel starting point $(\mathbf{A})$ and guide angle (B). 
by the posterior cruciate ligament, the anterior horn of the lateral meniscus and the medial tibial eminence) (Figure 7).

- Posterolateral widening of tibial tunnel converting it into a truncated oblique cone shape (Figure 8).

These modifications provide more oblique orientation for the femoral guide, which will yield more anatomic positioning of the graft.

\section{Femoral tunnel}

After drilling the tibial tunnel, a femoral guiding device is introduced through the tibial tunnel. Some modifications allow more anatomic inclination to the femoral tunnel, which are:

- Posterolateral notchplasty contouring the Gothic-shaped superolateral corner of the femoral notch to resemble a Roman arch. This will clean any osteophytes and bonny edges and allows more freely positioning of the femoral drill guide (Figure 9).

- The femoral guiding device should be $2 \mathrm{~mm}$ smaller than the size of tibial tunnel to allow more free mobility in the tunnel. This allows more inferior positioning of the guide and more oblique inclination of the graft.

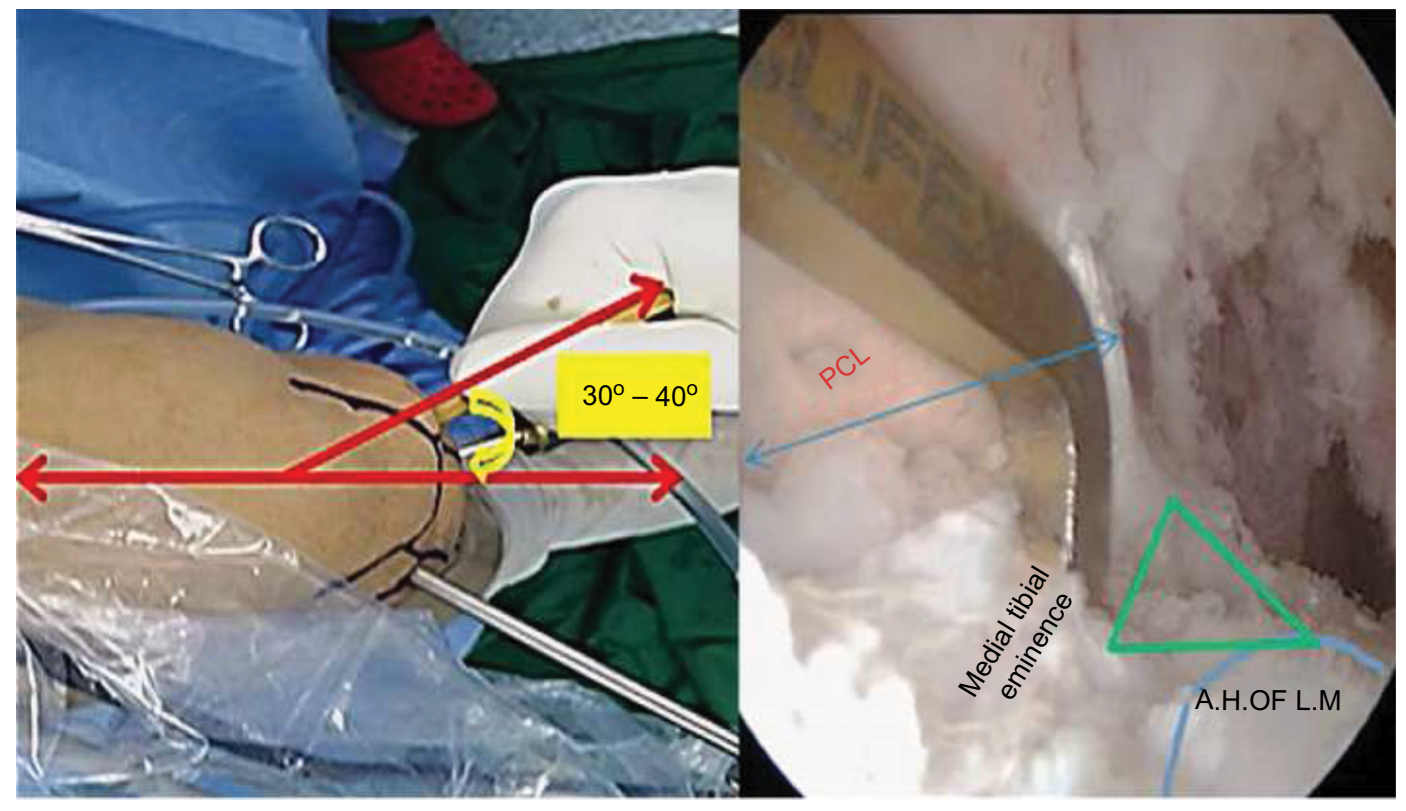

Figure 7 Tibial drill guide positioning.

Abbreviations: $\mathrm{PCL}$, posterior cruciate ligament; $\mathrm{AH}$ of $\mathrm{LM}$, anterior horn of lateral meniscus.

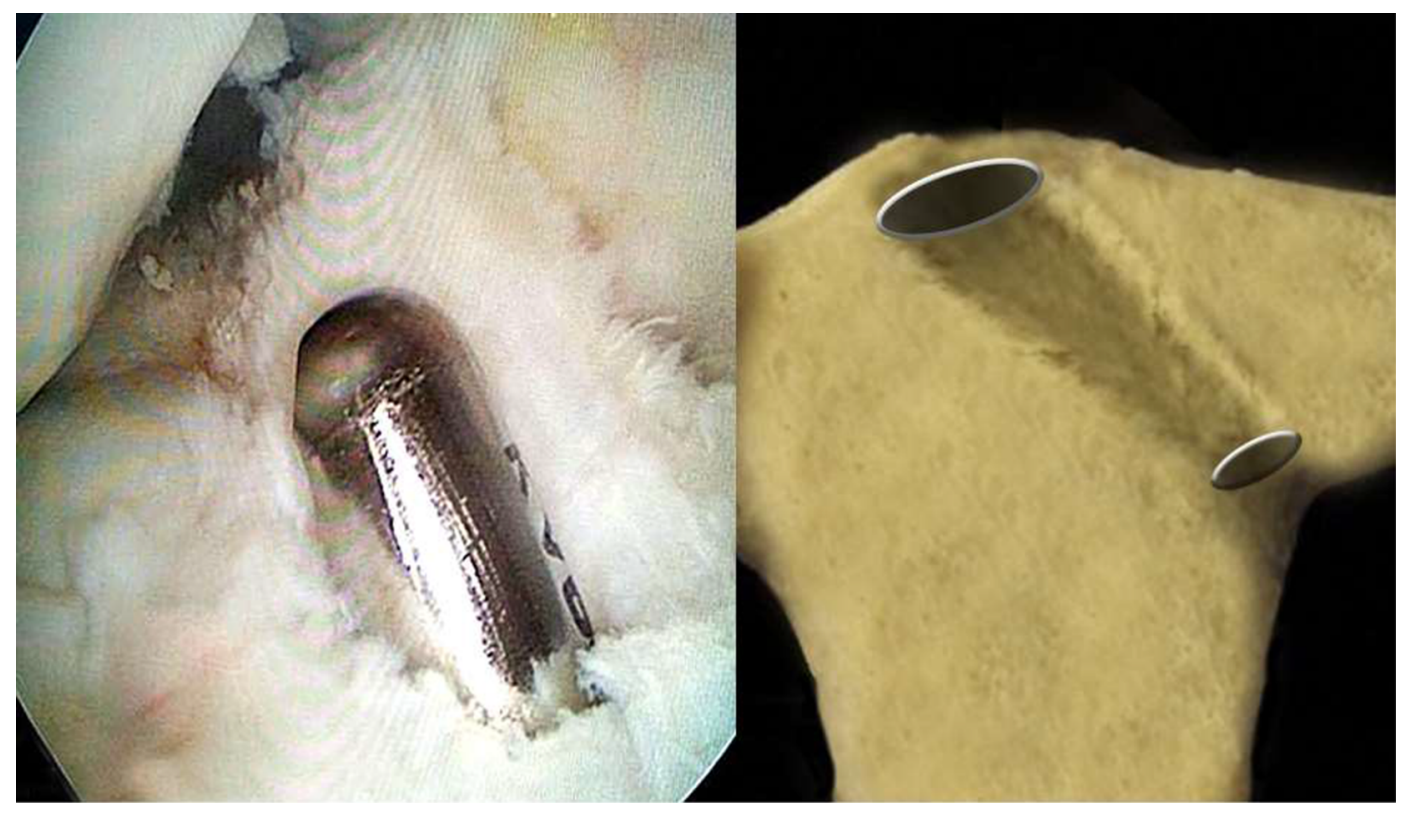

Figure 8 Posterolateral tibial tunnel widening. 
- External rotation of the femoral guide after hooking its shoulder over the top position will give extra few degrees of obliquity (Figure 10).

Following these steps will yield more obliquely oriented graft as shown in Figure 11.

\section{Data and statistical analysis}

All the data and results of the patients for both AAMPT and MTTT groups were gathered together in two separate master tables. Data were analyzed using Statistical Program for Social Science (SPSS) version 18.0. Quantitative data were displayed

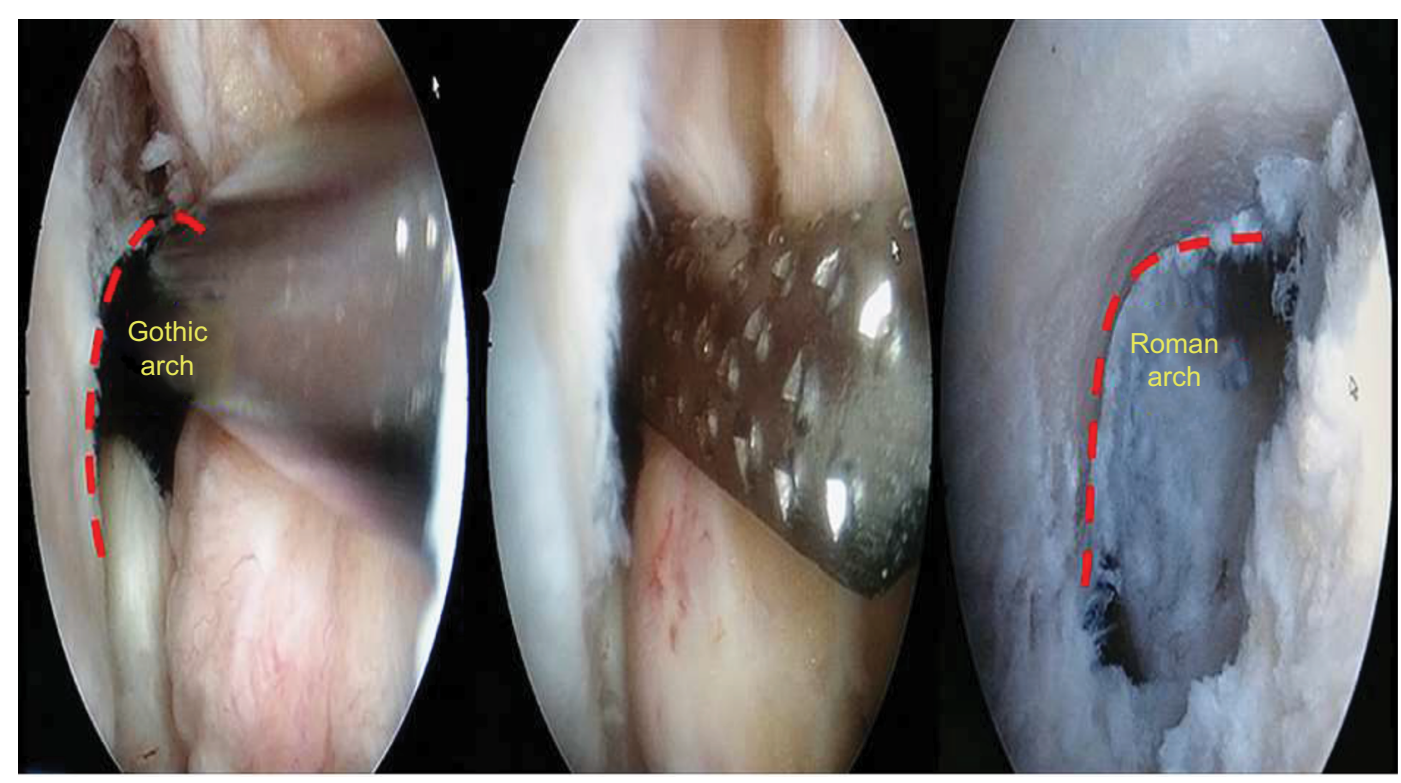

Figure 9 Femoral notchoplasty.

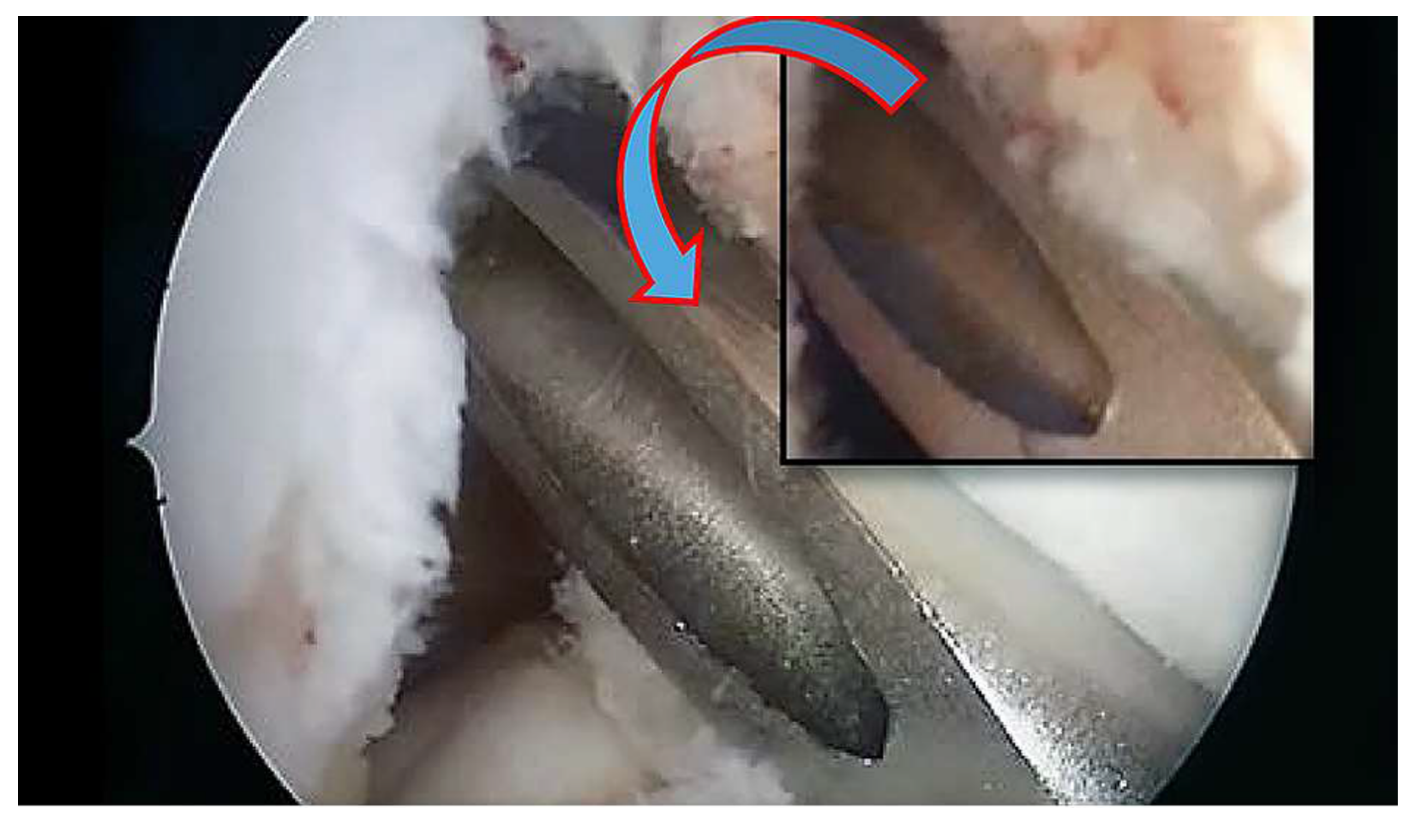

Figure 10 External rotation of the femoral guide. 
as the mean $\pm \mathrm{SD}$. Qualitative data were represented as frequency and percentage. The following tests were performed:

- Independent samples $t$-test of significance was applied when comparing two means.

- Chi-square $\left(\chi^{2}\right)$ test of significance was used to compare the proportions between two qualitative parameters.

- Probability ( $P$-value) was considered insignificant for values $>0.05$, significant for values $<0.05$, and highly significant for values $<0.001$.

\section{Results}

\section{Clinical examination}

There was an insignificant difference between the two groups regarding Lysholm and IKDC subjective scores $(P$-value $>0.05)$. Although the IKDC knee examination for one case in MTTT showed " $C$ " final evaluation, the final clinical assessment between the two groups showed no significant difference $(P$-value $>0.05)$. Patients' satisfaction and their functional performance were the same for both the groups (Figure 12).

\section{Radiological evaluation}

\section{Angles}

Graft inclination in AAMPT were significantly more oblique than those in MTTT $(P$-value $<0.001)$. The GIA mean value in MTTT was $23.76^{\circ}$ while in AAMPT, it was $28.8^{\circ}$. On the other hand, the FGA and TGA showed no significant difference between the two groups ( $P$-value $>0.05$; Figure 13$)$.

\section{TTP}

The TTP of the graft in the sagittal plane showed no significant difference between the two studied groups $(P$-value $>0.05)$. On the other hand, the graft in the MTTT method was located more medial on the tibia in the coronal plan (mean value of $43.4 \%$ ) than the graft in the AMP method (mean value of $44.9 \%)$ ). This was designed as part of the modified technique $(P$-value $<0.05)$.

\section{FTP}

The graft in MTTT was located more medial on the femur in the coronal plan (mean value of $43.6 \%$ ) than the graft in AAMPT (mean value of $38.5 \%$ ). Regarding location in the sagittal plane, the graft in MTTT (mean value of $75.7 \%$ ) had greater posterior location than that in AAMPT (mean value of $62.9 \%$, Figure 14). The anteromedial technique was capable of locating the graft in more anterior and lateral positions on the femoral side compared with the MTTT.

\section{Relation between ligament examination and subjective scores}

The final score of both Lysholm and IKDC subjective scoring systems showed a highly significant relationship in the

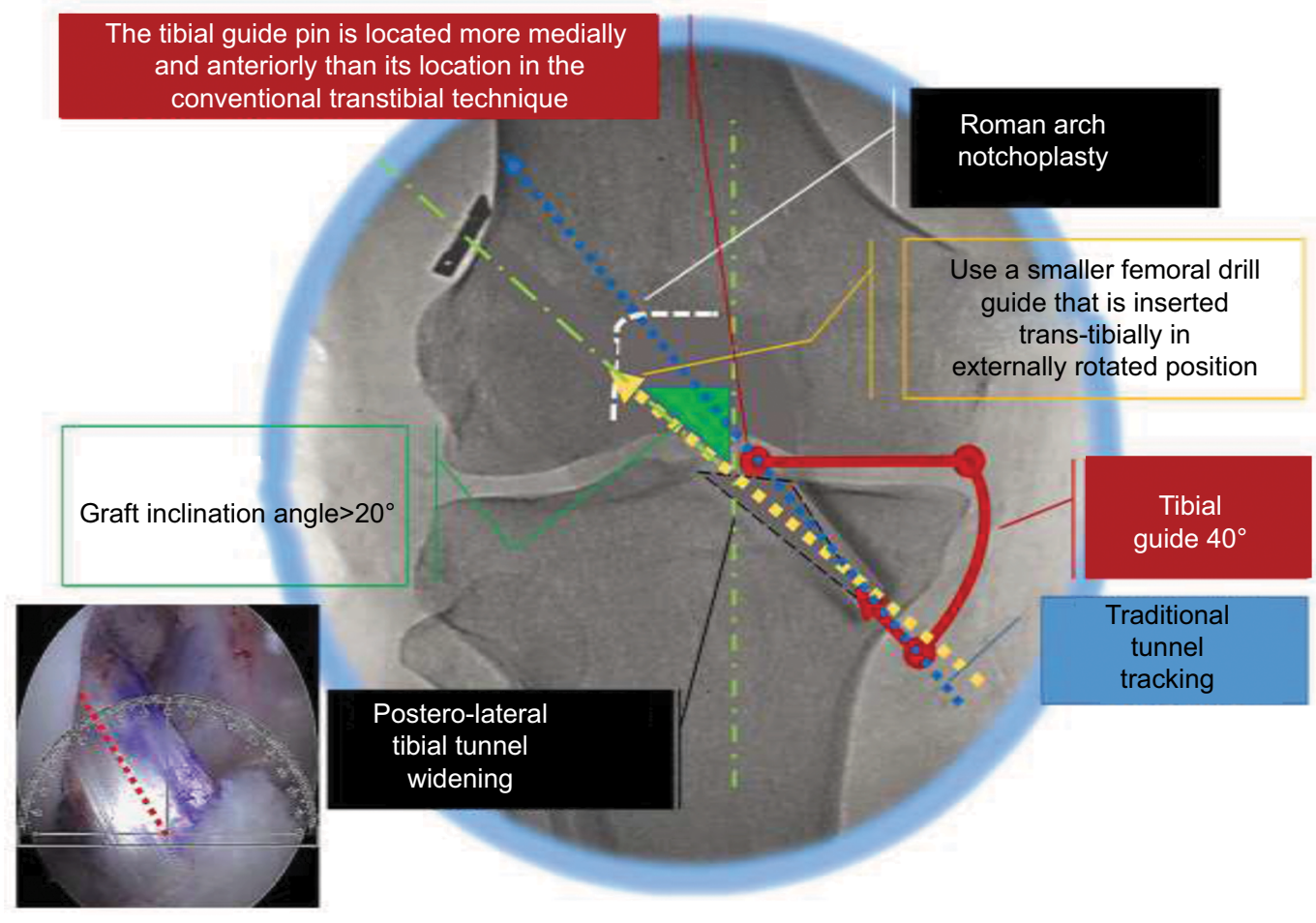

Figure I I Modifications steps in MTTT.

Abbreviation: MTTT, modified transtibial technique. 

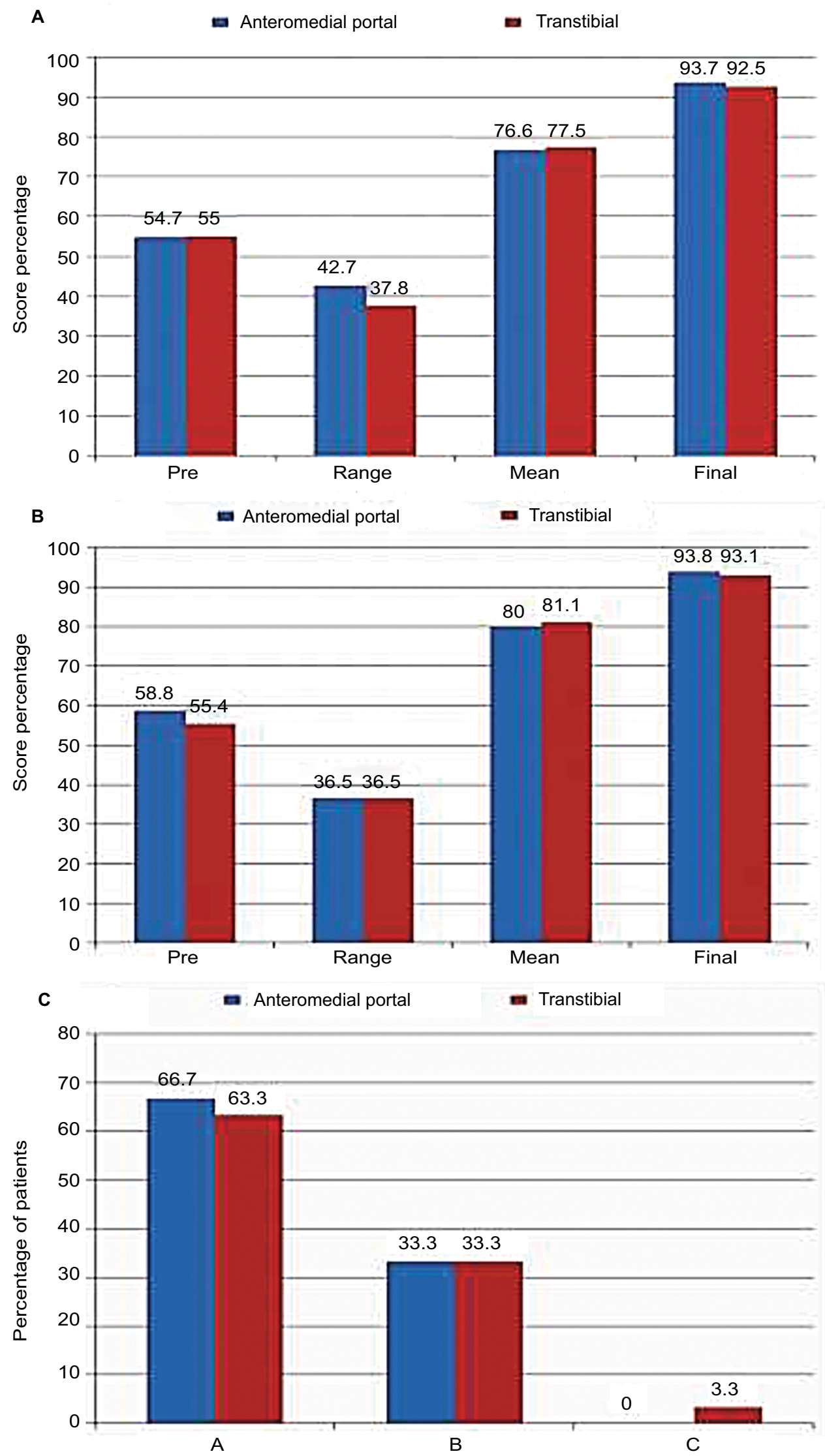

Figure 12 IKDC subjective score (A), Lysholm subjective score (B), and IKDC knee examination score (C).

Notes: $A, B, \& C$ are grading levels of clinical examination; $A$ is the best, $C$ is the worst and $B$ is intermediate.

Abbreviation: IKDC, International Knee Documentation Committee. 


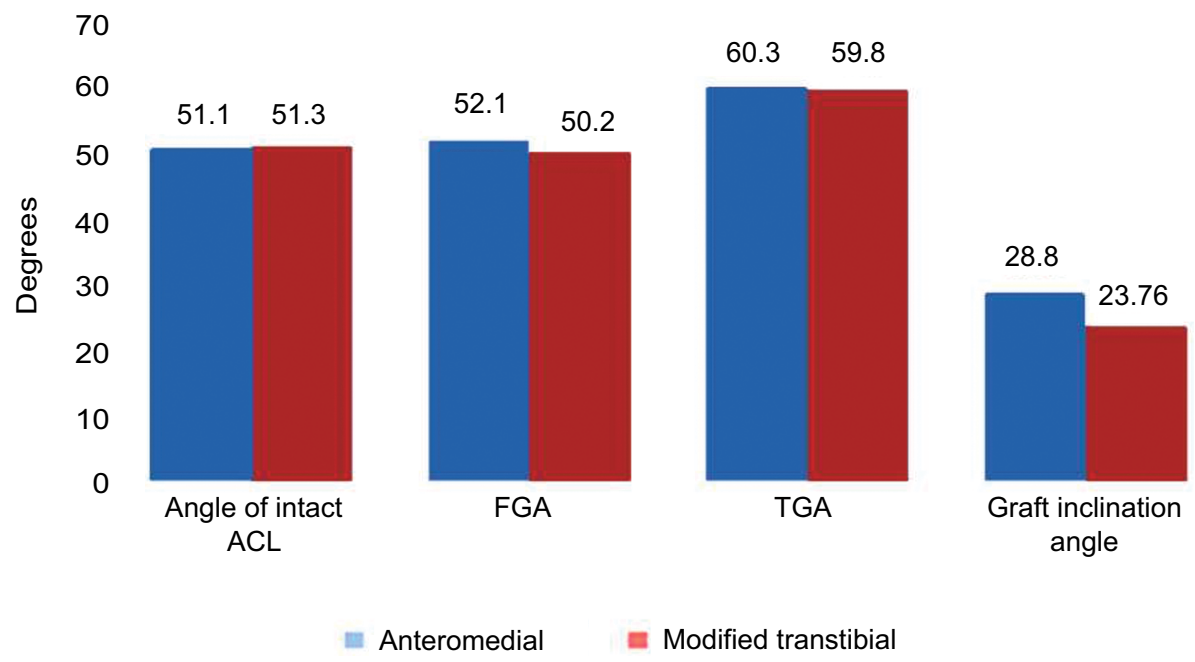

Figure 13 AAMPT vs MTTT regarding radiological angles.

Abbreviations: AAMPT, accessory anteromedial portal technique; MTTT, modified transtibial technique; ACL, anterior cruciate ligament; FGA, femoral graft angle; TGA, tibial graft angle.

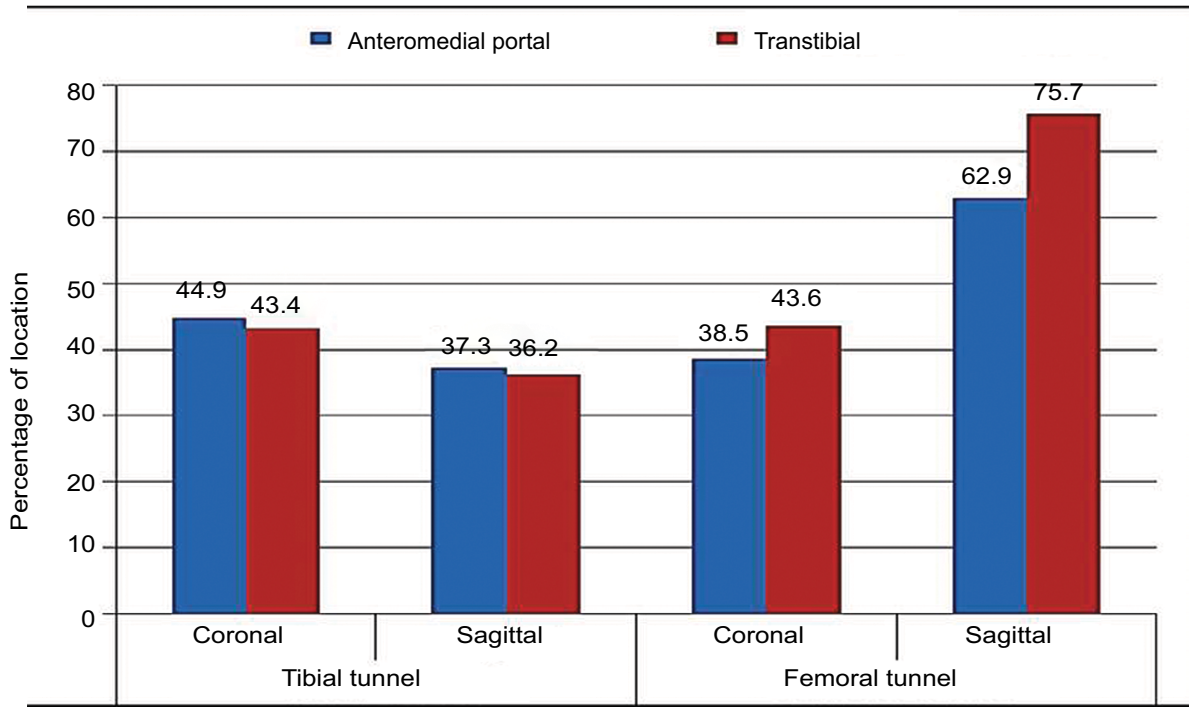

Figure I4 AAMPT vs MTTT regarding tunnel placement.

Abbreviations: AAMPT, accessory anteromedial portal technique; MTTT, modified transtibial technique.

ligamentous examination of the knee among the patients of both the groups $(P$-value $<0.001)$.

\section{Relation between one leg hop functional test and subjective scores}

There was a strong relationship between the ability to do "one leg hop functional test" and both Lysholm and IKDC final scores $(P$-value $<0.05)$.

\section{Relation between FGA and GIA}

Among the patients of the MTTT group, the FGA and the GIA in the coronal plane have a substantial relation to each other ( $P$-value $<0.001)$. On the other hand, this relation did not exist among patients of the AMP group ( $P$-value $>0.05)$. This indicates that the MTTT technique avoids acute bending of the graft at the femoral inlet which is one of the disadvantages of the anteromedial technique.

\section{Relation between preoperative and mean postoperative subjective scores}

There was a significant correlation between the preoperative and mean postoperative Lysholm and IKDC scores between the patients of both the groups $(P$-value $<0.05)$. Patients with low preoperative scores showed slower progression 
and improvement during the postoperative follow-up period, while those with high preoperative scores showed higher progress and improvement.

\section{Relation between preoperative and final postoperative subjective scores}

There was a significant correlation between the preoperative and final postoperative Lysholm and IKDC scores between the patients of both the groups $(P$-value $<0.05)$. Patients with low preoperative scores had low final postoperative scores, while those with higher preoperative scores had higher final postoperative scores and achievement.

\section{Discussion}

There is a never-ending controversy in the literature regarding the superiority of anteromedial technique over the transtibial technique in ACL reconstruction (Figure 15).

Many techniques have developed aiming at modifying the transtibial technique. ${ }^{24-28}$ These modifications aimed at putting the ACL graft at better anatomic positions than the traditional TT can do. The current study has offered some changes for the standard TT in simplified steps to add more obliquity and near anatomic femoral insertion of the graft.

Both MTTT and AAMPT groups had similar subjective results regarding the mean, range, and final values ( $P$-values $>0.05)$. Also, there was no significant difference in the results of clinical examination between the two groups. This regards knee effusion, passive motion defect, ligament examination, compartment findings, harvest site pathology, X-ray findings, and functional one leg hop test performance ( $P$-values $>0.05$ ). This indicates that the modified near anatomic TT technique "MTTT" succeeds to achieve similar functional results to the anatomic AM technique.

In spite of having a significant difference between the coronal GIA in the AAMPT group (mean of $28.8 \pm 3.4^{\circ}$ ) and the MTTT group (mean of $23.76 \pm 5.64^{\circ}$ ), both the techniques place the graft in more inclination than native ACL which was found to be $15.72 \pm 4.75^{\circ} .{ }^{29}$ MTTT in this study had GIA of $23.76^{\circ}$ which is higher than the angle of the traditional TTT $^{5,21,30,31}$ and lies in-between the other modified TTT studies $^{22,32,38}$ (values presented in the literature, Figure 16).

In the current study, the MTTT succeeded in positioning the graft and tunnel in more obliquity than the traditional non-anatomic TTT and better than most anatomic ranges. The MTTT had an FGA of $50.2 \pm 9.5^{\circ}$, which is more oblique than anatomic ranges $\left(60.7 \pm 4.2^{\circ}\right)^{33}$ but less than other modified techniques $\left(42.5 \pm 6.1{ }^{\circ}\right) .{ }^{26}$ Significantly, it is still far oblique than the vertical angles found in non-anatomic ranges $\left(82.8 \pm 12.5^{\circ}\right)$ and conventional TT techniques $\left(85.8 \pm 9.3^{\circ}\right) .^{33}$ On the contrary, the coronal FGA was found to be closely related to GIA in the MTTT which did not exist between the cases of AAMPT. This implies that the MTTT avoids acute

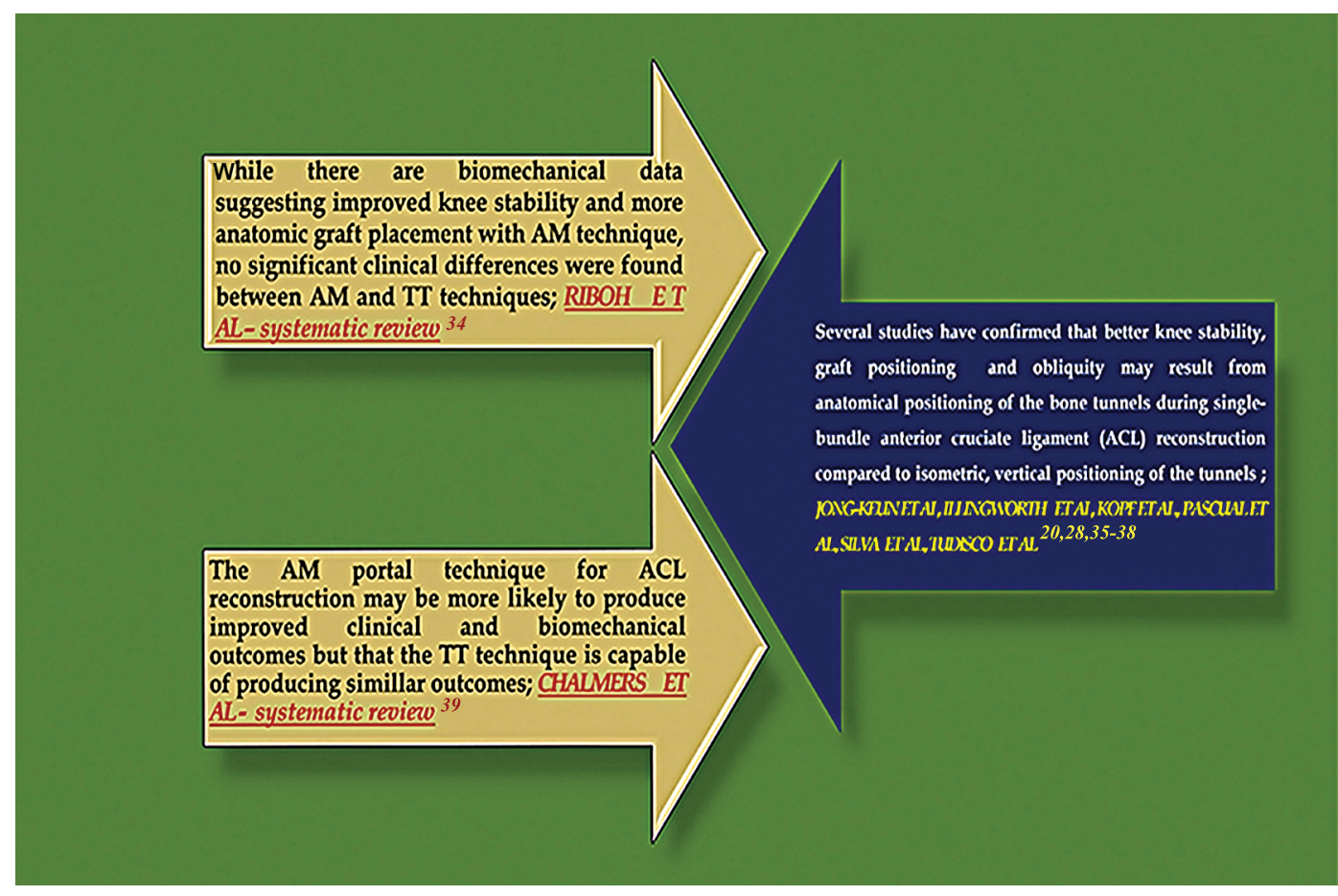

Figure I5 AAMPT vs TTT in literature.

Abbreviations: AM, anteromedial; TT, transtibial; AAMPT, accessory anteromedial portal technique; TTT, transtibial technique. 
pending of the graft at its entry through the femoral tunnel which is a common disadvantage of the AAMPT.

The sagittal TGA was found unrelated to the sagittal angle of the intact ACL in both the groups of our study ( $P$-value $>0.05)$. This implies that the traditional TTT through these tunnels may yield non-anatomic graft inclination. But because of the use of femoral drill guide in either free in AAMPT or transtibial modified in MTTT, the femoral tunneling does not follow the tibial tunnel in direction and more anatomically oriented femoral tunnels could be drilled and more anatomic graft positions could be achieved.
In the sagittal plane, the MTTT in the current study positions the tibial tunnel in a similar location to that of other MTTT and AMT (Figure 17). Also, it was found to be more anterior to that of other TTT, and it was more medial than all others in the coronal plane.

Regarding FTP, the MTTT in our study had significantly placed the graft in a medial $(43.6 \% \pm 2.3 \mathrm{SD})$ and posterior position $(75.7 \% \pm 5.6 \mathrm{SD})$ than that of the AAMPT (38.5\% $\pm 6.2 \mathrm{SD}$ and $62.9 \% \pm 5.3 \mathrm{SD}$, respectively) with a $P$-value $<0.001$. On the other hand, the MTTT graft was more anterior than in traditional TTT ${ }^{22,30}$ and other modified TTT $^{28}$ found in the literature (Figure 18).

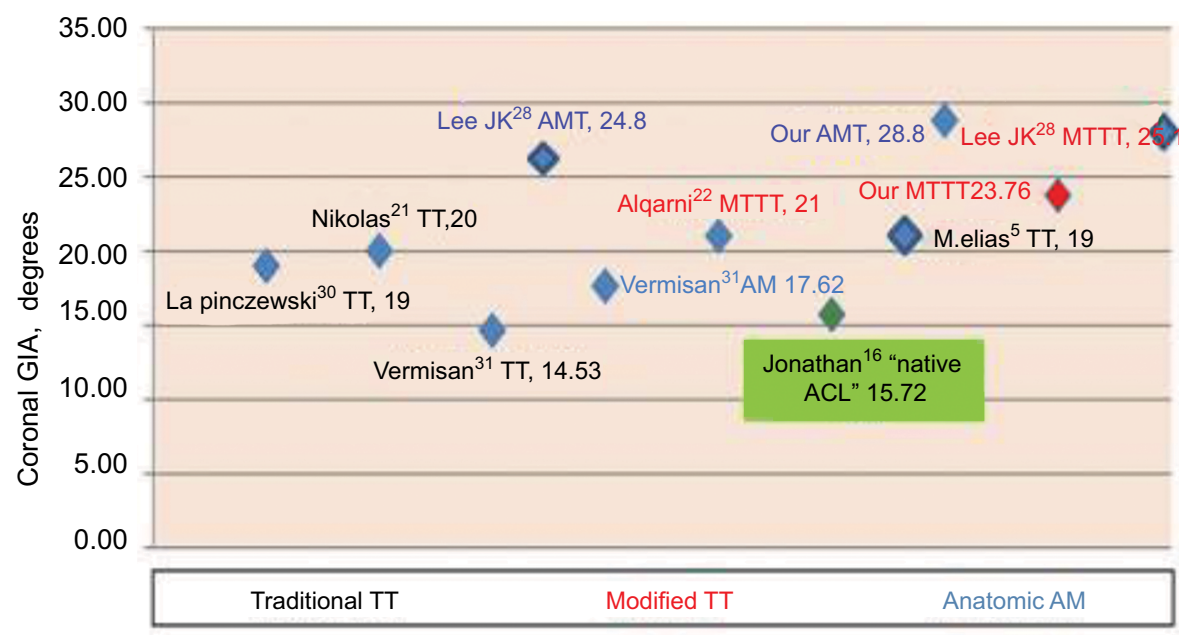

Figure 16 MTTT vs literature regarding GIA.

Notes: Green text is referring to the value of inclination angle of the intact $A C L$.

Abbreviations: MTTT, modified transtibial technique; GIA, graft inclination angle; AMT, anteromedial technique; $A C L$, anterior cruciate ligament.

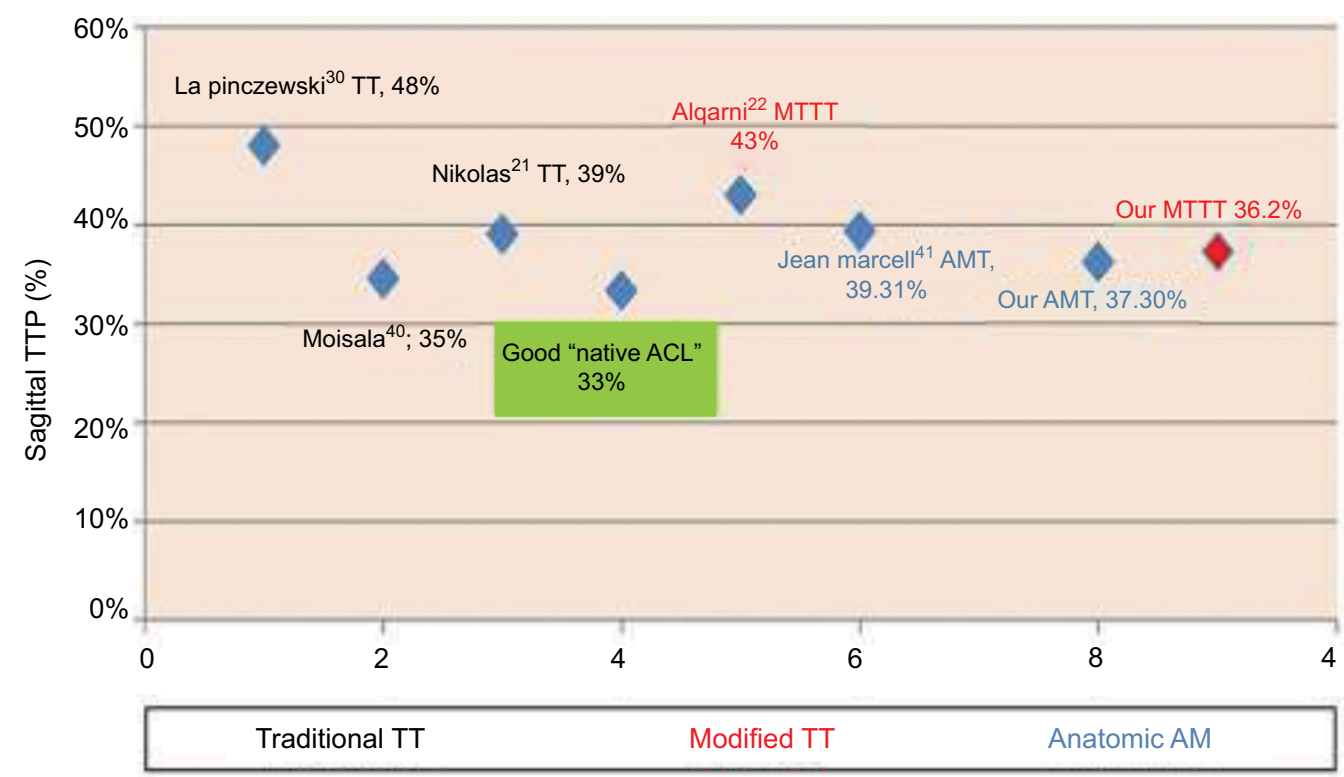

Figure 17 MTTT vs literature regarding TTP.

Notes: The green text is referring to the sagittal placement of the intact ACL on the tibial articular surface.

Abbreviations: MTTT, modified transtibial technique; TTP, tibial tunnel placement; AMT, anteromedial technique; ACL, anterior cruciate ligament. 


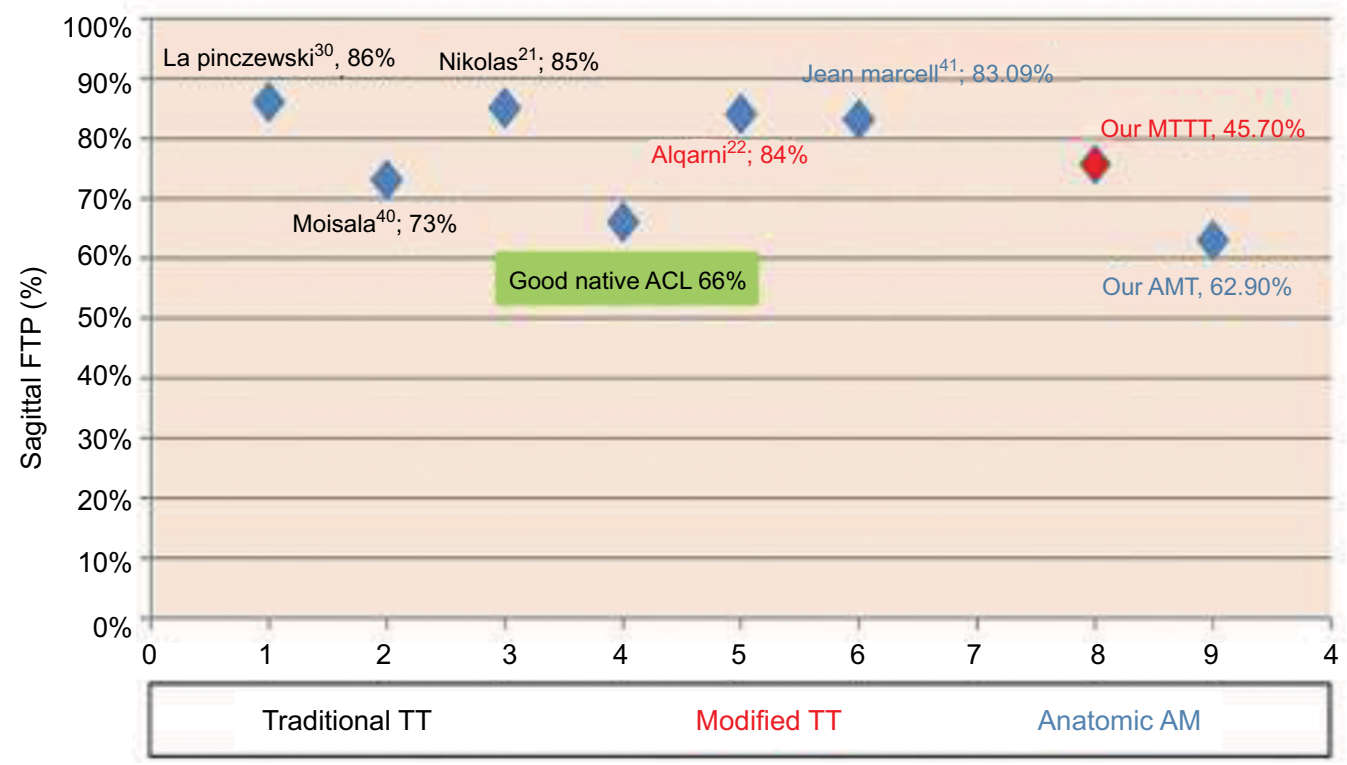

Figure 18 MTTT vs literature regarding FTP.

Notes: The green text is referring to the sagittal placement of the intact ACL on the femoral condylar surface.

Abbreviations: MTTT, modified transtibial technique; FTP, femoral tunnel placement; AMT, anteromedial technique; ACL, anterior cruciate ligament.

The patients' complaints and subjective scoring were found to be positively related to the graft stability showed by ligamentous examination $(P$-value $<0.001)$. This indicates the more stable the grafts are indicated by higher grades of ligamentous examination in the IKDC examination form, the less the complaints will be detected in the Lysholm and IKDC subjective forms. Also, the ability of the patients to achieve higher scores in the functional one leg hop test was affected by their subjective scores and subsequently by their graft stability $(P$-value $<0.05)$.

The subjective scoring of the patients in the preoperative state was found to affect both the mean and the final scores significantly, for both the groups of the study. Patients with better preoperative subjective state will have smoother postoperative period and better outcome, which could raise the importance of proper preoperative rehabilitation and early surgical intervention.

\section{Conclusion}

This study offers a modified technique for those who prefer, or are more accustomed to, the transtibial technique. These simple modifications would allow a near anatomic TTT with comparable results to the anatomic AMT and with reduced complications. The current modified technique may solve the problem of vertical graft positioning widely known for the
TTT. It may also overcome the challenges of the anteromedial technique, namely the difficulty in obtaining a clear view of the lateral wall of the notch, the horizontal trajectory of wire drilling and reaming that increases the risk of articular cartilage damage and posterior cortical breakthrough. Also the resultant acute pending of the inserted graft at its entry through the femoral tunnel will make the graft more jeopardized in the AAMPT.

As the condition of the knee before surgery was found to impact the recovery and the outcome significantly postoperatively, early surgical intervention and proper preoperative rehabilitation seems influential.

\section{Acknowledgments}

We would like to thank Dr Ahmed Al-Morrah, Professor of Orthopedic Surgery, Cairo University, Egypt, and Dr Hisham Mesbah, Professor of Orthopedic Surgery, Cairo University, Egypt for scientific supervision and critical review; Dr Mohamed Alaa Eldin Elgayar, Professor of Radiology and Medical Imaging, Zagazig University, Egypt for radiological assessment; and Dr Mazen Zedan, Consultant Pediatric Surgery, KFAFH, Saudi Arabia for the language review.

\section{Disclosure}

The authors report no conflicts of interest in this work. 


\section{References}

1. Duquin TR, Wind WM, Fineberg MS, Smolinski RJ, Buyea CM. Current trends in anterior cruciate ligament reconstruction. J Knee Surg. 2009;22:7-12.

2. Arnold MP, Kooloos J, Kampen A. Single-incision technique misses the anatomical femoral anterior cruciate ligament insertion: a cadaver study. Knee Surg Sports Traumatol Arthrosc. 2001;9:194-199.

3. Chhabra A, Kline AJ, Nilles KM, Harner CD. Tunnel expansion after anterior cruciate ligament reconstruction with autogenous hamstrings: a comparison of the medial portal and transtibial techniques. Arthroscopy. 2006;22:1107-1112.

4. Giron F, Buzzi R, Aglietti P. Femoral tunnel position in anterior cruciate ligament reconstruction using three techniques. A cadaver study. Arthroscopy. 1999;15:750-756.

5. Hantes ME, Zachos VC, Liantsis A, Venouziou A, Karantanas AH, Malizos KN. Differences in graft orientation using the transtibial and anteromedial portal technique in anterior cruciate ligament reconstruction: a magnetic resonance imaging study. Knee Surg Sports Traumatol Arthrosc. 2009;17:880-886.

6. Heming IF, Rand J, Steiner ME. Anatomical limitations of transtibial drilling in anterior cruciate ligament reconstruction. Am J Sports Med. 2007;35:1708-1715.

7. Loh JC, Fukuda Y, Tsuda E, Steadman RJ, Fu FH, Woo SL. Knee stability and graft function following anterior cruciate ligament reconstruction: comparison between 11 o'clock and 10 o'clock femoral tunnel placement. Arthroscopy. 2003;19:297-304.

8. Paessler H, Rossis J, Mastrokalos D, et al. Anteromedial versus transtibial technique for correct femoral tunnel placement during arthroscopic ACL reconstruction with hamstrings: an in vivo study. J Bone Joint Surg Br. 2004;86:S234.

9. Scopp JM, Jasper LE, Belkoff SM, Moorman CT 3rd. The effect of oblique femoral tunnel placement on rotational constraint of the knee reconstructed using patellar tendon autografts. Arthroscopy. 2004;20:294-299.

10. Bottoni CR, Rooney RC, Harpstrite JK, Kan DM. Ensuring accurate femoral guide pin placement in anterior cruciate ligament reconstruction. Am J Orthop. 1998;27:764-766.

11. Cha PS, Chhabra A, Harner CD. Single-bundle anterior cruciate ligament reconstruction using the medial portal technique. Oper Tech Orthop. 2005;15:89-95.

12. Gavriilidis I, Motsis EK, Pakos EE, Georgoulis AD, Mitsionis G, Xenakis TA. Transtibial versus anteromedial portal of the femoral tunnel in ACL reconstruction: a cadaveric study. Knee. 2008;15:364-367.

13. Harner CD, Honkamp NJ, Ranawat AS. Anteromedial portal technique for creating the anterior cruciate ligament femoral tunnel. Arthroscopy. 2008;24:113-115.

14. Steiner ME. Independent drilling of tibial and femoral tunnels in anterior cruciate ligament reconstruction. J Knee Surg. 2009;22:171-176.

15. Dargel J, Schmidt-Wiethoff R, Fischer S, Mader K, Koebke J, Schneider T. Femoral bone tunnel placement using the transtibial tunnel the anteromedial portal in ACL reconstruction: a radiographic evaluation. Knee Surg Sports Traumatol Arthrosc. 2009;17: 220-227.

16. Jonathan K. Jennings, MD, Daniel P, D’Alessandro DF, Peindl RD, Piasecki DP. Transtibial versus anteromedial portal ACL reconstruction: is a hybrid approach the best? Orthop J Sports Med. 2017;5:2325967117719857.

17. International Knee Documentation Committee - Orthopaedic Scores-2000 IKDC knee form. Available from: https://www.aaos.org/ uploadedFiles/PreProduction/Quality/Measures/IKDCEnglishUS.pdf. Accessed September 6, 2018.

18. Tegner Lysholm knee scoring scale. Available from: https://stfsportsmed.com/wp-content/uploads/Lysholm-Knee-Scale.pdf. Accessed September 6, 2018.

19. Werstine M. Functional testing guidelines for ACL reconstruction, testing instructions for clinicians. Fowler Kennedy Sports Medicine Clinic Physiotherapy Department; 2015. Available from: http://www.fowlerkennedy.com/wp-content/uploads/2015/11/FUNCTIONAL-TESTINGGUIDELINES-FOR-ACL-RECONSTRUCTION-November-2015.pdf.
20. Illingworth KD, Hensler D, Working ZM, Macalena JA, Tashman S, Fu FH. A simple evaluation of anterior cruciate ligament femoral tunnel position: the inclination angle: the inclination and femoral tunnel angle. Am J Sports Med. 2011;39:2611-2618.

21. Gougoulias N, Khanna A, Griffiths D, Maffulli N. ACL reconstruction: can the transtibial technique achieve optimal tunnel positioning? A radiographic study. Knee. 2008;15:486-490.

22. Algarni D. Anterior cruciate ligament reconstruction: can optimal graft placement be achieved with a free-hand drilled transtibial technique? Saudi J Sports Med. 2014;1:39-43.

23. Rue JP, Lewis PB, Parameswaran AD, Bach BR Jr. Single-bundle anterior cruciate ligament reconstruction: technique overview and comprehensive review of results. J Bone Joint Surg Am. 2008;90(Suppl 4):67-74.

24. Piasecki DP, Bach BR Jr. Anatomical single-bundle anterior cruciate ligament reconstruction with a transtibial technique. Am JOrthop (Belle Mead NJ). 2010;39:302-304.

25. Youm YS, Cho SD, Lee SH, Youn $\mathrm{CH}$. Modified transtibial versus anteromedial portal technique in anatomic single-bundle anterior cruciate ligament reconstruction, comparison of femoral tunnel position and clinical results. Am J Sports Med. 2014;42:2941-2947.

26. Youm YS, Cho SD, Eo J, Lee KJ, Jung KH, Cha JR. 3D CT analysis of femoral and tibial tunnel positions after modified transtibial single bundle ACL reconstruction with varus and internal rotation of the tibia. Knee. 2013;20:225-298.

27. Sohn OJ, Lee DC, Park KH, Ahn HS. Comparison of the modified transtibial technique, anteromedial portal technique and outside-in technique in ACL reconstruction. Knee Surg Relat Res. 2014;26:241-248.

28. Lee JK, Lee S, Seong SC, Lee MC. Anatomic single-bundle ACL reconstruction is possible with the use of the modified transtibial technique: a comparison with the anteromedial transportal technique. J Bone Joint Surg Am. 2014;96:664-672.

29. Reid JC, Yonke B, Tompkins M. The angle of inclination of the native ACL in the coronal and sagittal planes. Knee Surg Sports Traumatol Arthrosc. 2017;25:1101-1105.

30. Pinczewski LA, Salmon LJ, Jackson WFM, von Bormann RPB, Haslam P, Tashiro S. Endoscopic anatomic landmarks for tunnel placement in ACL Reconstruction and their relationship to 7-year clinical outcome. J Bone Joint Surg. 2008;90:172-179.

31. Vermesan D, Inchingolo F, Patrascu JM, et al. Anterior cruciate ligament reconstruction and determination of tunnel size and graft obliquity. Eur Rev Med Pharmacol Sci. 2015;19:357-364.

32. Seon JK, Song EK, Park CH, Kang KD. Can anatomical femoral tunnel position improve clinical outcomes in anterior cruciate ligament reconstruction. Sports Medicine and Arthroscopy. Paper 102:1034. Available from: https://www.aaos.org/education/anmeet/ education/sports_medicine_arthoroscopy_abstracts.pdf. Accessed September 6, 2018

33. Illingworth KD, Hensler D, Working ZM, Casagranda B, Tashman S. ACL inclination angle on MRI and femoral tunnel angle on AP x-ray: a comparison study with tunnel positions on 3D CT in Single Bundle ACL Reconstruction. ORS 2011 Annual Meeting. Available from: https:// www.aaos.org/education/anmeet/education/sports_medicine_arthoroscopy_abstracts.pdf. Accessed September 6, 2018.

34. Riboh JC, Hasselblad V, Godin JA, et al. Transtibial versus independent drilling techniques for anterior cruciate ligament reconstruction: a systematic review, meta-analysis, and metaregression. Am J Sports Med. 2013; 41:2693-2702.

35. Kopf S, Forsythe B, Wong AK, et al. Nonanatomic tunnel position in traditionaltranstibial single-bundle anterior cruciate ligament reconstruction evaluated by three-dimensional computed tomography. J Bone Joint Surg Am. 2010;92:1427-1431.

36. Pascual-Garrido C, Swanson BL, Swanson KE. Transtibial versus low anteromedial portal drilling for anterior cruciate ligament reconstruction: a radiographic study of femoral tunnel position. Knee Surg Sports Traumatol Arthrosc. 2013;21(4):846-850. 
37. Silva A, Sampaio R, Pinto E. ACL reconstruction: comparison between transtibial and anteromedial portal techniques. Knee Surg Sports Traumatol Arthrosc. 2012;20(5):896-903.

38. Tudisco C, Bisicchia S. Drilling the femoral tunnel during acl reconstruction: transtibial versus anteromedial portal techniques. Orthopedics. 2012;35(8):E1166-E1172.

39. Chalmers PN, Mall NA, Cole BJ, et al. Anteromedial versus transtibial tunnel drilling in anterior cruciate ligament reconstructions: a systematic review. Arthroscopy. 2013;29:1235-1242.
40. Moisala AS, Jarvela T, Harilainen A, Sandelin J, Kannus P, Jarvinen M. The effect of graft placement on the clinical outcome of the anterior cruciate ligament reconstruction: a prospective study. Knee Surg Sports Traumatol Arthrosc. 2007;15(7):879-887.

41. Dambrós JM, Florêncio R, Valadão Lopes Júnior O et al. Radiological analysis of bone tunnel position in anterior cruciate ligament reconstruction surgery: comparison between the open technique and arthroscopy via an anteromedial portal. Revista Brasileira de Ortopedia. 2011;46(3) $270-275$.
The Open Access Journal of Sports Medicine is an international, peer-reviewed, open access journal publishing original research, reports, reviews and commentaries on all areas of sports medicine. The journal is included on PubMed. The manuscript management system is completely online and includes a very quick and fair

\section{Dovepress}

peer-review system. Visit http://www.dovepress.com/testimonials.php to read real quotes from published authors. 